\title{
Some immunological properties of lipopolysaccharide from Acinetobacter baumannii
}

\author{
APOLINARIA GARCÍA, FERNANDO SALGADO, HENRY SOLAR, CARLOS L. GONZÁLEZ, RAÚL \\ ZEMELMAN and ANGEL OÑATE
}

Departamento de Microbiología, Facultad de Ciencias Biológicas, Universidad de Concepción, Casilla 152-C, Concepción, Chile

\begin{abstract}
Acinetobacter baumannii, mainly biotype 9, is an important nosocomial opportunist pathogen in Chile and other countries. The biological basis of its virulence and prevalence is still unknown. As lipopolysaccharide (LPS) is often associated with virulence, some biological properties of purified LPS from seven nosocomial isolates, comprising four isolates of $A$. baumannii biotype 9, two isolates of biotype 8 and one isolate of biotype 1, were investigated. LPS was extracted and purified from each isolate by the hot phenol-water method, and its ability to elicit a mitogenic response and to induce the synthesis of $\alpha$ tumour necrosis factor (TNF- $\alpha$ ) in mouse spleen cells was determined. Activity was evaluated in vivo by determining the splenic index in comparison with LPS from Salmonella Typhimurium. All seven LPS samples were mitogenic on the basis of cellular proliferation experiments and six induced synthesis of TNF- $\alpha$. Similar results were obtained in in-vivo experiments in which LPS induced spleen cell growth, as shown by determination of the splenic index. These results suggest that the LPS of $A$. baumannii might contribute to the pathogenic properties of this species.
\end{abstract}

\section{Introduction}

Acinetobacter baumannii, mainly biotype 9, has become an important opportunist pathogen in Chilean hospitals [1-3]. This species is also being reported with increasing frequency world-wide as an aetiological agent of hospital-acquired infections [4-6]. Its importance as a nosocomial pathogen is reflected in its increasing frequency of isolation and its multiresistance to antimicrobial agents $[1,3,6,7]$. Studies conducted with clinical isolates of Acinetobacter inoculated in to mice have shown that its virulence is similar to that of Escherichia coli, Serratia marcescens or Pseudomonas aeruginosa. However, the biological basis of the virulence of $A$. baumannii is still unknown [8]. One possibility is that lipopolysaccharide (LPS) might play a role in virulence, as has been shown for other bacterial species [8-11].

LPS from gram-negative bacteria contains a mixture

Received 7 July 1998; accepted 3 Sept 1998.

Corresponding author: Dr A. García. of molecules with side chains of varying lengths [1214]. This molecular heterogeneity results in the classical 'ladder-like' patterns observed following SDS-PAGE and staining with silver nitrate [12-14]. LPS has several biological activities that can be measured either in vitro or in vivo $[15,16]$. Thus, blastogenicity can be evaluated by determining growth of spleen cells in vivo [17]. Results of these studies show a good correlation with in-vitro tests such as those for mitogenicity induced by lipid A with B cells or induction of cytokine synthesis, i.e., tumour necrosis factor $\alpha$ (TNF- $\alpha$ ) and interleukin- $\alpha$ (IL- $1 \alpha$ ), in mouse spleen cells [17].

LPS containing long O-specific sugar chains (S-type LPS) has been associated with virulence in other bacteria $[15,16]$, and previous studies in this laboratory have shown that nosocomial isolates of $A$. baumannii from Chile also produce an S-type LPS [18]. The aim of this work was to evaluate, both in vivo and in vitro, the effect of challenging cells with purified LPS from $A$. baumannii. The splenic index, the lymphoproliferative response and the TNF- $\alpha$ synthesis induced by the LPS were used as indicators of the biological activity. 


\section{Materials and methods}

Mice

Female BALB/c mice aged 6-8 weeks were used to investigate the immunological properties of LPS. These mice were housed and handled according to the animal research guidelines of the Universidad de Concepción.

\section{Bacterial strains and growth conditions}

Four isolates of A. baumannii biotype 9, two isolates of biotype 8 and one isolate of biotype 1 were included in the study. These isolates were from the hospitals of three cities located in distant areas of Chile, and were identified and biotyped according to Bouvet and Grimont $[19,20]$. Inocula were prepared by growing the isolates in Trypticase-Soy Broth (Life Technologies) at $37^{\circ} \mathrm{C}$, with rotatory shaking at $150 \mathrm{rpm}$. The isolates were maintained in glycerol $20 \% \mathrm{v} / \mathrm{v}$ at $-20^{\circ} \mathrm{C}$.

\section{LPS extraction}

LPS was extracted from 10-L cultures as described by Westphal and Jann [21], followed by treatment with lysozyme (Sigma) $25 \mathrm{mg} / \mathrm{L}$, DNAase I (Sigma) $25 \mathrm{mg} / \mathrm{L}$ and RNAase $\mathrm{H}$ (Sigma) $25 \mathrm{mg} / \mathrm{L}$ for $3 \mathrm{~h}$ at $37^{\circ} \mathrm{C}$, and then incubation with proteinase $\mathrm{K}$ (Sigma) $50 \mathrm{mg} / \mathrm{L}$ for $2 \mathrm{~h}$ at $60^{\circ} \mathrm{C}$. Proteinase $\mathrm{K}$ was removed by washing with pyrogen-free water and centrifuging at $105000 \mathrm{~g}$, after which the LPS fractions were lyophilised and kept at $-20^{\circ} \mathrm{C}$ until used.

\section{Purity of LPS preparations}

Samples of all LPS preparations were analysed by SDS-PAGE $[22,23]$ and by protein quantitation $[24]$ to evaluate the extent of any contamination with protein, as well as by absorbance at $260 \mathrm{~nm}$ to determine contamination with DNA [25].

\section{B-cell proliferation}

Assays were performed as described previously [17]. Briefly, mice were killed by cervical dislocation and their spleens were removed and homogenised aseptically. Spleen cells were suspended in RPMI 1640 medium containing fetal calf serum $10 \% \mathrm{v} / \mathrm{v}$, penicillin $100 \mathrm{U} / \mathrm{ml}$, streptomycin $100 \mathrm{mg} / \mathrm{L}$ and amphotericin B $0.25 \mathrm{mg} / \mathrm{L}$ (all constituents from Sigma) and adjusted to $4 \times 10^{6}$ cells $/ \mathrm{ml}$. Equal $100-\mu 1$ portions of cell suspension and LPS preparation (containing $1 \mu \mathrm{g}$ ) were incubated at $37^{\circ} \mathrm{C}$ in $\mathrm{CO}_{2} 5 \% \mathrm{v} / \mathrm{v}$ in air in 96-well plates (Nunclon, Roskilde, Denmark). The optimal concentration of each LPS preparation was determined by testing concentrations of $0.1,1.0,10$ and $100 \mu \mathrm{g} / \mathrm{ml}$. After incubation for $72 \mathrm{~h}$, cultures were pulse-labelled with $0.5 \mu \mathrm{Ci}$ of ${ }^{3} \mathrm{H}$-thymidine $(50 \mathrm{Ci} /$ $\mathrm{mmol}$; Amersham) and incubation was continued for a further $8 \mathrm{~h}$. The cells were then harvested by filtration on to glass fibre filter paper with a cell harvester, and the associated radioactivity was measured with a liquid scintillation counter (Analyzer 1600; TR Packard). Commercial LPS from Salmonella Typhimurium strain SL 1181 (Re mutant) (Sigma) and LPS from a smooth strain were used as positive controls, with RPMI 1640 medium alone as a negative control. All assays were conducted in triplicate.

\section{TNF- $\alpha$ determination}

Cells were stimulated with the same protocol (see above) and TNF- $\alpha$ was determined in the supernates of 24-h cell cultures [26] with a Mouse TNF- $\alpha$ ELISA Kit (Genzyme, Cambridge, MA, USA), used according to the manufacturer's directions. The same controls were included.

\section{Splenic index}

The ability of LPS preparations to induce an increase in spleen weight was determined by calculating the splenic index. Groups of five female mice were inoculated intraperitoneally with $1 \mu \mathrm{g}$ of LPS and killed after 4 days. The weight of the animals and of their spleens was determined, and the splenic index was calculated as the ratio between these two parameters (spleen weight:mouse weight) [17]. Positive and negative controls were those described for the cell proliferation assay.

\section{Statistical analysis}

Statistical analysis of all the results was by the Tukey test, used in conjuction with the Systat program [27].

\section{Results}

Results were obtained with LPS preparations that had been treated with proteinase $\mathrm{K}$ to remove protein contamination. Absence of protein in the LPS preparations was demonstrated on gels stained with Coomassie Blue R-250, while the absence of nucleic acid was demonstrated by determining absorbance at $260 \mathrm{~nm}$. All the LPS from the nosocomial isolates examined appeared to contain S-type LPS, as indicated by the ladder-like pattern obtained on SDS-PAGE gels after silver staining (data not shown)

\section{Proliferation assay}

All the LPS preparations were mitogenic for B-cells, but differences were observed in their biological activity (Fig. 1). Four isolates (HS-54, HJJA-9, HJJA7 and HS-4) showed mitogenic activity similar to that of LPS from the smooth strain of $S$. Typhimurium, whereas LPS from the other three isolates (UC-25, HJJA-8 and 95-52) showed mitogenic activity similar 


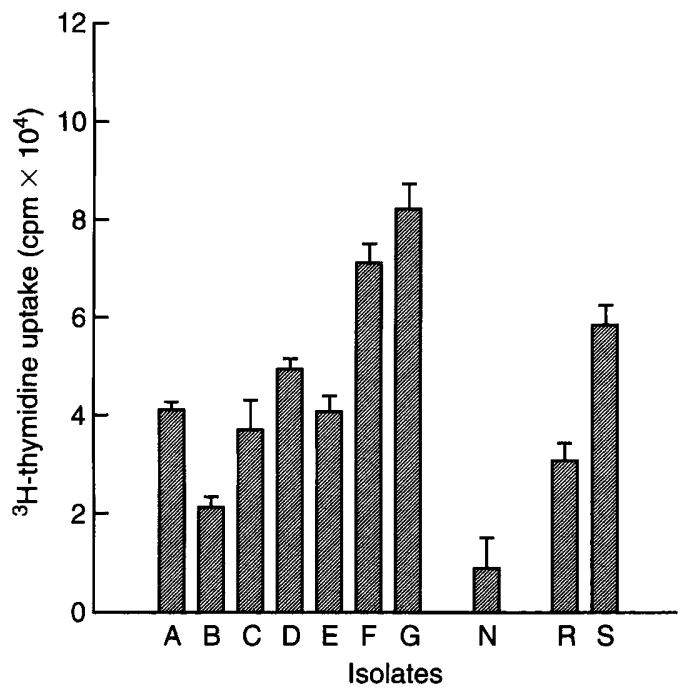

Fig. 1. Uptake of ${ }^{3} \mathrm{H}$-thymidine by mouse spleen cells $\left(4 \times 10^{6}\right.$ cells $\left./ \mathrm{ml}\right)$ challenged with purified LPS preparations obtained from $A$. baumannii isolates. Each value represents the mean of two readings. A, isolate HS-54, B, HJJA-9; C, HJJA-7, D, UC-25; E, HS-4; F, HJJA-8; $\mathbf{G}, 95-52 ; \mathbf{N}$, negative control (RPMI medium); $\mathbf{S}, S$. Typhimurium (smooth); R, $S$. Typhimurium (Re mutant).

to that of the Re mutant of $S$. Typhimurium. The differences in mitogenicity observed between the LPS preparations and the negative control were statistically significant $(p \leqslant 0.05)$ as determined by the Tukey test [27].

\section{TNF- $\alpha$ assay}

Six LPS preparations from $A$. baumannii induced cytokine synthesis in spleen cell cultures (Fig. 2), with induction levels similar to those observed with the LPS from the smooth strain of $S$. Typhimurium, but higher

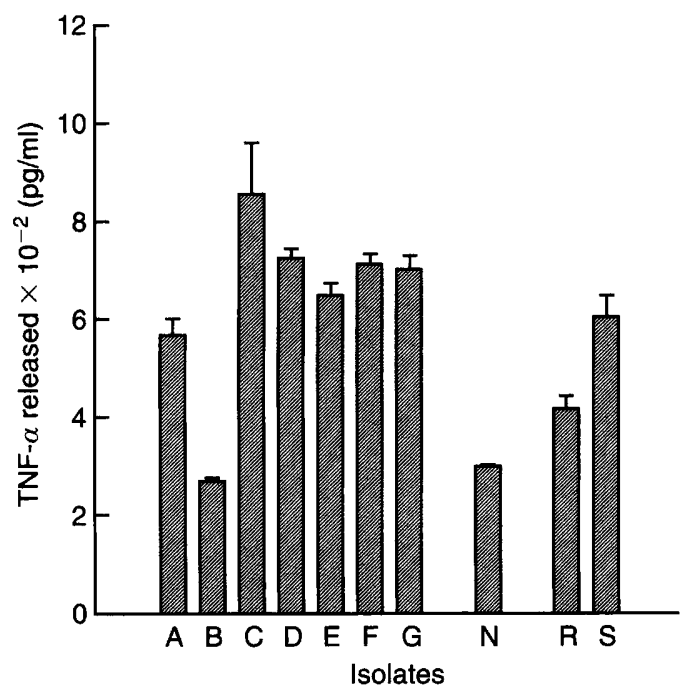

Fig. 2. TNF- $\alpha$ released from mice spleen cells $(4 \times$ $10^{6}$ cells $/ \mathrm{ml}$ ). Each value represents the mean of two readings. Isolate abbreviations as for Fig. 1. than those induced by LPS from the Re mutant of $S$. Typhimurium. However, all these differences were statistically significant when compared with the negative control. Only LPS from isolate HJJA-9 behaved differently in this assay, with no significant induction of TNF- $\alpha$ observed in the spleen cells after challenge.

\section{Splenic index}

To assess whether LPS showed activity in vivo, mice were inoculated intraperitoneally with LPS preparations to evaluate induction of spleen growth. Most LPS preparations induced spleen growth, as indicated by the relatively high splenic index observed in comparison with the negative control (Fig. 3), with values obtained with LPS from five $A$. baumannii isolates being similar to that obtained with LPS from the smooth strain of $S$. Typhimurium. LPS from isolate HJJA-9 yielded a significantly lower index $(p \leqslant 0.05)$, and LPS from one isolate (HS-4) did not induce spleen growth, even though it corresponds to a smooth type of LPS [18].

\section{Discussion}

Although A. baumannii has been studied intensively during the last decade in an attempt to understand its virulence factors, antibiotic resistance mechanisms and epidemiological aspects, the importance of these organisms has only been recognised recently. This study examined the potential contribution of LPS to the virulence of A. baumannii. Previously, Aucken and Pitt [28] reported only R-type LPS from several $A$. baumannii isolates, but other studies have suggested that Acinetobacter spp. are able to produce S-form LPS $[18,29-31]$. If so, LPS may contribute to the

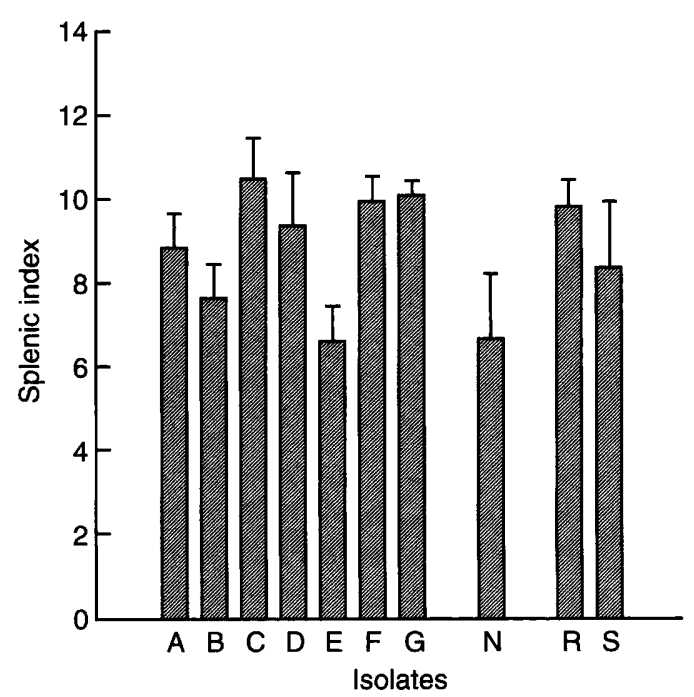

Fig. 3. Splenic index (spleen weight:mouse weight) of mice challenged with preparations obtained from $A$. baumannii isolates. The mice used showed slight differences in overall weight, but these were not statistically significant. Isolate abbreviations as for Fig. 1. 
pathogenic properties of these micro-organisms during serious nosocomial infections.

The differences in the ability of LPS from different isolates of $A$. baumannii to elicit mitogenic activity could be caused by variations in the fatty acid content of lipid A, as has been demonstrated for the LPS of Bacteroides spp. [26]. On the other hand, the high mitogenic activity induced by LPS from isolates HJJA-8 and 95-52 might be the consequence of the experimental quality of the lipid A [26] as well as to differences in the O-antigens [17]. There is a need to further purify lipid A from the rest of the molecule to validate the data obtained with the complete LPS molecule.

TNF- $\alpha$ is considered to be a pivotal cytokine in the host response to endotoxin [32]. The results in this paper indicate that, in this respect, LPS from $A$. baumannii behaves in a similar fashion to LPS from other gram-negative species. Again, the lack of TNF- $\alpha$ inducing activity of isolate HJJA-9 might result from differences in the structure of lipid $\mathrm{A}$, as has been demonstrated in B. fragilis [33].

In-vivo studies also showed a high biological activity of LPS as an endotoxin. As this activity was homogeneous for the different isolates, it might be speculated that $A$. baumannii contains a toxic lipid A, mainly because spleen growth is related to this part of the macromolecule [17]. Brade and Galanos [34] compared the biological activities of LPS and lipid A from Acinetobacter with those from Salmonella. In agreement with the present results, these authors also reported that both LPS and lipid A from Acinetobacter exhibited lethal toxicity in mice, pyrogenicity in rabbits, complement inactivation in vitro, a local Shwartzmann reaction, mitogenicity for mouse-spleen B lymphocytes and a positive Limulus amoebocyte lysate test [34], with a pattern similar to that obtained with LPS and lipid A from Enterobacteriaceae. Lastly, the lack of activity of LPS from the smooth isolate HS-4 may be a consequence of a lipid A of low toxigenicity or result from the presence of different types of repetitive sugars in the LPS which are not able to modulate the biological activity of the lipid A. The high variability of the O-antigen in the LPS molecules of different clinical isolates has been pointed out by Pantophlet et al. [35]. Overall, the results presented in the present paper suggest an important role for the LPS from nosocomial strains of $A$. baumannii as a virulence factor in vivo. We conclude that the synthesis of endotoxin might be an important factor responsible for the severity of disease observed during $A$. baumannii sepsis.

This work was supported by grants 2950031,1951044 and 1961146 from the Fondo Nacional de Investigación Científica y Tecnológica (FONDECYT) de Chile. Some of the results were communicated in the Terceras Jornadas Rioplatenses de Microbiología (Abstract no. A18, Buenos Aires, Argentina, October 1997).

\section{References}

1. Zemelman R, Bello H, Domínguez M, González G, Mella S, García A. Activity of imipenem, third-generation cephalosporins, aztreonam, and ciprofloxacin against multi-resistant Gramnegative bacilli isolated from Chilean hospitals. J Antimicrob Chemother 1993; 32: 413-419.

2. Domínguez M, González G, Bello $\mathrm{H}$ et al. Identification and biotyping of Acinetobacter spp. isolated in Chilean hospitals. $J$ Hosp Infect 1995; 30: 267-271.

3. Bello H, González G, Domínguez M, Zemelman R, García A, Mella S. Activity of selected $\beta$-lactams, ciprofloxacin, and amikacin against different Acinetobacter baumannii biotypes from Chilean hospitals. Diagn Microbiol Infect Dis 1997; 28: 183-186.

4. Bergogne-Bérézin E, Joly-Guillou ML, Vieu JF. Epidemiology of nosocomial infections due to Acinetobacter calcoaceticus. $J$ Hosp Infect 1987; 10: 105-113.

5. Bergogne-Bèrèzin $\mathrm{E}$, Joly-Guillou $\mathrm{ML}$. Hospital infection with Acinetobacter spp.: an increasing problem. $J$ Hosp Infect 1991: 18 Suppl A: 250-255.

6. Seifert H, Baginski R, Schulze A, Pulverer G. Antimicrobial susceptibility of Acinetobacter species. Antimicrob Agents Chemother 1993; 37: 750-753.

7. Ritter E, Thurm V, Becker-Boost E, Thomas P, Finger H, Wirsing von Konig $\mathrm{CH}$, Epidimischer vor kommen multiresistenter Acinetobacter baumannii stamme auf einer neonatologischen intensiustation. [Epidemic occurences of multiresistant Acinetobacter baumannii strains in a neonatal intensive care unit.] Zentralbl Hyg Unmeltmed 1993; 193: 461-470.

8. Avril J-L, Mesnard R. Factors influencing the virulence of Acinetobacter. In: Towner KJ, Bergogne-Bérézin E, Fewson CA (eds) The biology of Acinetobacter. Taxonomy, clinical importance, molecular biology, physiology, industrial relevance. New York, Plenum Press. 1991: 77-82.

9. Möller, G, Sjöberg O, Andersson J. Immunogenicity, tolerogenicity, and mitogenicity of lipopolysaccharides. In: Kass E, Wolff S (eds) Bacterial lipopolysaccharide. Chicago, University of Chicago Press. 1973: 44-48.

10. Mäkelä $\mathrm{H}$, Valtonen $\mathrm{V}$, Valtonen $\mathrm{M}$. Role of $\mathrm{O}$-antigen (lipopolysaccharide) factors in the virulence of Salmonella. In: Kass E, Wolff S (eds) Bacterial lipopolysaccharide. Chicago, University of Chicago Press. 1973: 73-77.

11. Peavy D, Shadns J, Adler W, Smith R. Selective effects of bacterial endotoxins in various subpopulations of lymphoreticular cells. In: Kass E, Wolff S (eds) Bacterial lipopolysaccharide. Chicago, University of Chicago Press. 1973: 83-91.

12. Tsai C-M, Frasch CE. A sensitive silver stain for detecting lipopolysaccharides in polyacrylamide gels. Anal Biochem 1982; 119: 115-119.

13. Jann B, Reske K, Jann K. Heterogeneity of lipopolysaccharides. Analysis of polysaccharide chain lengths by sodium dodecylsulphate-polyacrylamide gel electrophoresis. Eur $J$ Biochem 1975: 60: 239-246.

14. Hitchcock PJ, Brown TM. Morphological heterogenicity among Salmonella lipopolysaccharide chemotypes in silver-stained polyacrylamide gels. $J$ Bacteriol 1983; 154: 269-277.

15. Odumeru JA, Wiseman GM, Ronald AR. Relationship between lipopolysaccharide composition and virulence of Haemophilus ducreyi. J Med Microbiol 1987; 23: 155-162.

16. Viriyakosol S, Kirkland TN. The N-terminal half of membrane CD14 is a functional cellular lipopolysaccharide receptor. Infect Immun 1996; 64: 653-656.

17. Folch $\mathrm{H}$, Oñate $A$. Propiedades mitogénicas y caracterización de diferentes fracciones polisacáridas obtenidas de dos especies de Brucella. Arch Med Vet 1995; 27: 85-91.

18. García A, Guzmán J, Dominguez M, Bello H, González G, Zemelman R. Electrophoretic patterns of lipopolysaccharide of Acinetobacter baumannii from different sources. Biomed Lett 1996; 53: 115-120.

19. Bouvet PJM, Grimont PAD. Taxonomy of the genus Acinetobacter with the recognition of Acinetobacter baumannii sp. nov., Acinetobacter haemolyticus sp. nov.; Acinetobacter johnsonii sp. nov., and Acinetobacter junii sp. nov., and emended descriptions of Acinetobacter calcoaceticus and Acinetobacter Iwoffii. Int $J$ Syst Bacteriol 1986; 36: 228-240.

20. Bouvet PJM, Grimont PAD. Identification and biotyping of clinical isolates of Acinetobacter. Ann Inst Pasteur Microbiol 1987; 138: $569-578$ 
21. Westphal O, Jann K. Bacterial lipopolysaccharides. Extraction with phenol-water and further applications of the procedure. In: Whistler R (ed) Methods in carbohydrate chemistry. New York, Academic Press. 1965: 83-91.

22. Laemmli UK. Cleavage of structural proteins during the assembly of the head of bacteriophage T4. Nature 1970; 227: $680-685$.

23. Fomsgaard A, Freundenberg MA, Galanos C. Modification of the silver staining technique to detect lipopolysaccharide in polyacrylamide gels. J Clin Microbiol 1990; 28: 2627-2631.

24. Markwell MAK, Haas SM, Bieber LL, Tolbert NE, A modification of the Lowry procedure to simplify protein determination in membrane and lipoprotein samples. Anal Biochem 1978; 87: 206-210.

25. Sambrook J, Fritsch EF, Maniatis T (eds). Molecular cloning: a laboratory manual, 2nd edn. Cold Spring Harbor, Cold Spring Harbor Laboratory Press. 1989: E.5.

26. Delahooke DM, Barclay GR, Poxton IR. A re-appraisal of the biological activity of bacteroides LPS. J Med Microbiol 1995; 42: $102-112$.

27. Wilkinson L. Systat. The system for statistics. Evanston II: Systat 1990.

28. Aucken HM, Pitt TL. Lipopolysaccharide profile typing as a technique for comparative typing of Gram-negative bacteria. $J$ Clin Microbiol 1993; 31: 1286-1289.

29. Borneleit P, Kleber H-P. The outer membrane of Acinetobacter: structure-function relationships. In: Towner $\mathrm{KJ}$, BergogneBérézin E, Fewson CA (eds) The biology of Acinetobacter. Taxonomy, clinical importance, molecular biology, physiology, industrial relevance. New York, Plenum Press. 1991: 259-271.

30. Haseley SR, Holst O, Brade H. Structural studies of the Oantigenic polysaccharide of the lipopolysaccharide from Acinetobacter (DNA group 11) strain 94 containing 3-amino3,6-dideoxy-D-galactose substituted by the previously unknown amide-linked L-2-acetoxypropionic acid or L-2-hydroxypropionic acid. Eur J Biochem 1997; 247: 815-819.

31. Vinogradov EV, Pantophlet R, Dijkshoorn L, Brade L, Holst O, Brade H. Structural and serological characterisation of two Ospecific polysaccharides from Acinetobacter. Eur $J$ Biochem 1997; 239: 602-619.

32. Henderson B, Poole S, Wilson M. Bacterial modulins: a novel class of virulence factors which cause host tissue pathology by inducing cytokine synthesis. Microbiol Rev 1996: 60: 316-341.

33. Lindberg AA, Weintraub A, Zähringer U, Rietschel ET. Structure-activity relationships in lipopolysaccharides of $\mathrm{BaC}$ teroides fragilis. Rev Infect Dis 1990; 12 Suppl 2: S133-S141.

34. Brade H, Galanos C. Biological activities of the lipopolysaccharide and lipid A from Acinetobacter calcoaceticus. J Med Microbiol 1983; 16: 211-214.

35. Pantophlet R, Brade L, Dijkshoorn L, Brade H. Specificity of rabbit antisera against lipopolysaccharide of Acinetobacter. $J$ Clin Microbiol 1998; 36: 1245-1250. 